\title{
Morphometric Study of Lateral Ventricles of Brain by MRI in Healthy Adults in Northern Zone of Bangladesh
}

\author{
Shahin Sharmin, ${ }^{\text {Akhtari Afroz, }}{ }^{2}$ Md. Atiqur Rahman, ${ }^{3}$ Syed Amanul Islam ${ }^{4}$
}

\section{ABSTRACT}

Background \& Objective: The present study was done to provide information about the morphometric measurement of lateral ventricles of human brain in relation to age and sex in northern Bangladeshi people.

Methods: This cross-sectional study was conducted in the Department of Anatomy, Rajshahi Medical College, Rajshahi over a period one year from July 2014 to June 2015. All patients attending at Radiology \& Imaging Department of Rajshahi Medical College Hospital and at different private hospitals and clinics of Rajshahi city and had normal MRI scan of brain were the study population. A total of 60 individuals of both sexes and age ranging between 18-50 years were included in the study. Having obtained ethical clearance from the Ethical Committee and verbal consent from the patients, the data collection was commenced. Patients were asked to lie on the MRI table in supine position with head fixed and coil placed around the head. MRI was done with MRI machine (Airis II Hitachi 0.3 Tesla) and images were taken by T1WI, T2WI, STAIR, FLAIR. Images were taken from axial, sagittal and coronal planes with sequence slice thickness being $7 \mathrm{~mm}$. From the images of axial slices, six proper slices were selected.

Result: Age distribution of the subjects with respect to sex shows that nearly two-thirds (63.3\%) of the female subjects were 30 or younger than 30 years old, whereas $50 \%$ of the male subjects were early middle-aged $(p=0.110)$. The mean lengths of frontal horn of right and left lateral ventricles in male subjects were significantly greater than those in female subjects ( $p=0.002$ and $p=0.001$ respectively). Likewise, the right and left ventricular bodies in male subjects were significantly longer than those of their female counterparts ( $p=0.033$ and $p=0.012$ respectively). The length of frontal horn of the lateral ventricles was found to increase with age up to 40 years in both right and left ventricles and then it began to decrease. The mean lengths of frontal horn of right and left lateral ventricles at ages $\leq 30,31-40$ and $>40$ years were $27.25,28.74$ and $26.0 \mathrm{~mm}$ and $27.57,28.93$ and $27.19 \mathrm{~mm}$ respectively. While the three measures of length of frontal horn of right lateral ventricles were significantly heterogeneous $(p=0.049)$, the three measures of length of frontal horn of left lateral ventricles were not significantly different $(p=0.141)$. The mean lengths of body of right and left lateral ventricles at different ages were $40.40,43.98,45.11 \mathrm{~mm}$ and $41.06,44.52$ and $45.21 \mathrm{~mm}$ respectively ( $p=0.001$ and $=0.001$ respectively).

Conclusion: The present study concluded that the lateral ventricles vary in size within certain limit according to age, sex and laterality. All the parameters of lateral ventricles (lengths of frontal horn, length of ventricular body) were significantly larger in males than those in females. While the length of frontal horn of the lateral ventricles (of both sides) increases in size up to the age of 40 years and thereafter regresses, the length of ventricular body bears a linear relationship with age throughout life-span.

Key words: Lateral ventricles, morphometric study, brain, MRI, healthy adults, northern zone of Bangladesh etc.

\section{Authors' information:}

'Dr. Shahin Sharmin, MBBS, M Phil, Assistant Professor, Department of Anatomy, Rajshahi Medical College, Rajshahi

${ }_{2}^{2}$ Professor Dr. Akhtari Afroz, MBBS, M Phil, Department of Anatomy, Barind Medical College Rajshahi

${ }^{3}$ Dr. Md. Atiqur Rahman, MBBS, M Phil, Assistant Professor, Department of Anatomy, Ad-dinAkij Medical College, Khulna

${ }^{4}$ Dr. Syed Amanul Islam, MBBS, M Phil, Associate Professor, Department of Anatomy, Shatkhira Medical College, Shatkhira, Khulna

Correspondence: Dr. Shahin Sharmin, Phone:+8801711100917E-mail: s.sharmin1965@gmail.com 


\section{INTRODUCTION :}

The ventricular system is a set of communicating cavities within the brain. These structures are responsible for the production, transport and removal of cerebrospinal fluid, which bathes the central nervous system. There are four cerebral ventricles: the paired lateral ventricles, the third and the fourth ventricles. The two lateral ventricles, located within the cerebrum, are relatively large and C-shaped, roughly wrapping around the dorsal aspects of the basal ganglia. The successive generation of neurons gives rise to the 6-layered structure of the neocortex, constructed from inside out during development. Each lateral ventricle extends into the frontal, temporal and occipital lobes via the frontal (anterior), temporal (inferior), and occipital (posterior) horns respectively. The "body" and "atrium" are situated between the anterior and posterior horns. The lateral ventricles both communicate via the interventricular foramina of Monro with the third ventricle (found centrally within the thalamus). The third ventricle communicates via the cerebral (located within the mid brain) with the fourth ventricle, found within the hindbrain (Fig.1A). The three foramina to the subarachnoid space permit cerebrospinal fluid (CSF) produced in the ventricles to surround the brain stem, cerebellum, and cerebral cortex. The fourth ventricle is also continuous with the central canal, allowing CSF to bathe the inner surface of the spinal cord as well. ${ }^{1}$

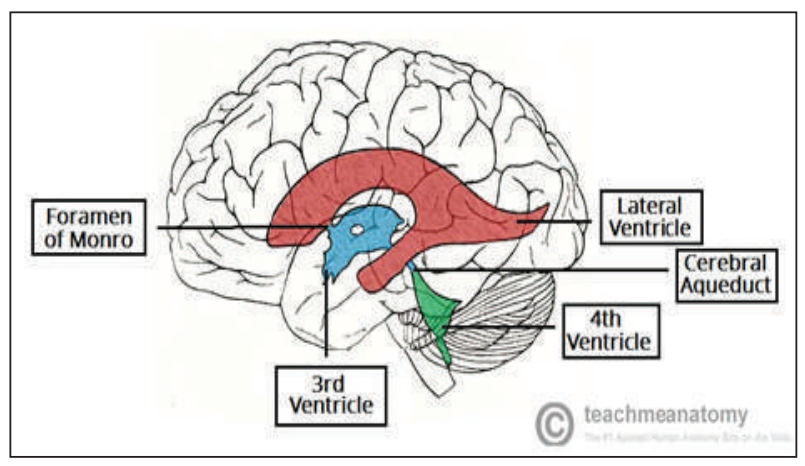

Fig. 1A: ventricular system of the brain

The ventricular system develops from the single cavity formed from the hollow neural tube. Early in development, the cavity within the neural tube (which forms the ventricular space) in different regions within its wall differentiate to form choroid plexus, a modified vascular structure which produce CSF (Fig.1B). With the progress of development, the space within the spinal cord turns into central canal. As the brain and spinal cord grow, this space makes up the majority of the nervous system by volume (ventricles of brain and central canal of the spinal ( cord). ${ }^{2}$

Glydensted ${ }^{3}$ studied the brains of 100 normal adults with Computed Tomography and found that the left lateral ventricle was larger than right lateral ventricle in both sexes and both lateral ventricles are larger in males than in females. The linear measurement of lateral ventricles demonstrated positive correlation to size of the cranium, while width of the third ventricle was independent of size of the skull. Galwer and associates ${ }^{4}$ found that there is a degree of asymmetry in the lateral ventricular contour.

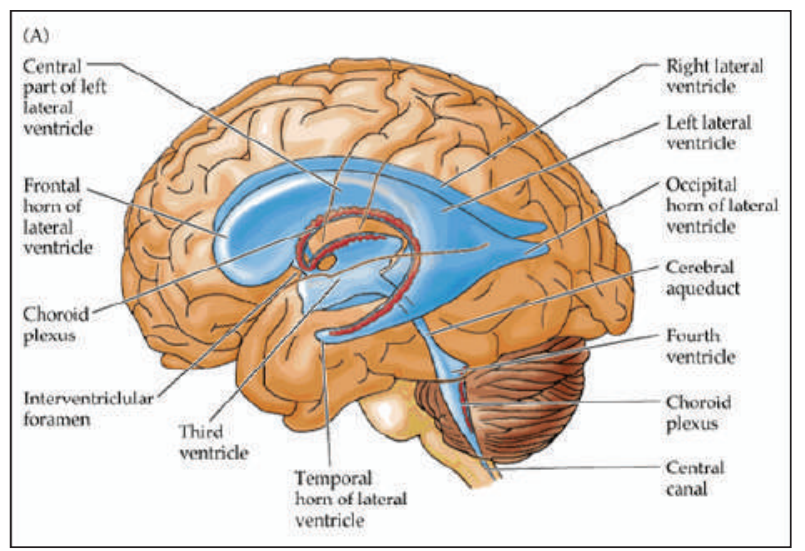

Fig. 1B: Ventricular system of the brain

Study of CAT scans of the ventricles in the late 1970 s revolutionized the study of mental disorder. Researchers found that individuals with schizophrenia had (in terms of group averages) enlarged ventricles compared to healthy subjects, although the enlargement of the ventricles is a cause or a result of schizophrenia has not yet been ascertained. ${ }^{5,6}$ Several studies $7,8,9$ have clearly shown an increase in the CSF spaces in dementia, especially in Alzheimer's $\&$ Parkinson's disease. According to Corsellis ${ }^{10}$ and Creasey and Rapoport ${ }^{11}$ this was due to reduction in the size of nerve cells. Haaga (1994) reported ventricular enlargement to be a more sensitive indicator of cortical atrophy due to increasing age and dementias. Studies ${ }^{12,13}$ have shown larger lateral ventricles in epilepsy and depression. 
According to Schochet ${ }^{14}$ the brain undergoes many gross and histopathologic changes with advancing age, and in various dementias, with regression of brain tissue leading to ballooning of the third ventricle and rounding of the angles of the lateral ventricles. LeMay ${ }^{15}$ attributed this ballooning of the third ventricle to a regression of the median nuclei of the thalami and a progressive diminution of the massa intermedia that joins them. There was alteration in the brain matter morphology and size and shape of ventricular system in chronic alcoholics. ${ }^{16,17}$ Morphometric analysis of ventricular system is also helpful in the diagnosis and classification of hydrocephalus and in the assessment and follow-up of enlargement of ventricular system during therapy (ventricular shunts). ${ }^{18}$ Medora and associates ${ }^{19}$ studied the morphometric measurement of ventricular system of brain by $\mathrm{CT}$ which has clinical correlation in diagnosis, treatment and surgical interventions.

Pneumoencephalography and ventriculography are the older techniques of visualizing the ventricular system by injecting air through lumbar puncture under local anaesthesia. ${ }^{20}$ Ventricular system can also be studied by two dimensional ultrasonic studies especially in children. ${ }^{21}$ In recent years, CT scan and MRI have replaced the older methods of studying ventricular system. Now a days, magnetic resonance imaging (MRI) has superseded the use of CAT in research into the role of ventricular abnormalities in various diseases. The present study was intended to provide more information regarding the size of normal lateral ventricles of brain in various age and sex group of Bangladeshi people residing in northern zone by MRI scan which is presently the most appropriate noninvasive technique of morphometric assessment of lateral ventricle.

\section{METHODS:}

This cross-sectional study was conduct the Department of Anatomy, Rajshahi Medical College, Rajshahi over a period on year from July 2014 to June 2015. All patients attending at Radiology \& Imaging Department of Rajshahi Medical College Hospital and at different private hospitals and clinics of Rajshahi city and had normal MRI scan of brain were the study population. All the individuals of both sexes and age, ranging between 18-50 years were included in the study. However, head injuries, cerebral ischemia or haemorrhagic infarction, intracranial space occupying lesion, previous intracranial surgeries were excluded. A total of 60 such individuals were consecutively included. Having obtained ethical clearance from the Ethical Committee and verbal consent from the patients, the data collection was started. Then detailed history (name, age, sex and other systemic diseases) was taken from the patients followed by physical examination. Before entering into MRI room, all metallic materials were removed. The patients were asked to lie on the MRI table in supine position with head fixed and coil placed around the head. Movement of the patient was not allowed to avoid image artifact. MRI was done with MRI machine (Arise II Hitachi 0.3 Tesla) and images were taken by T1WI, T2WI, STAIR, FLAIR. Images were taken from axial, sagittal and coronal planes with sequence slice thickness being $7 \mathrm{~mm}$. From the images of axial slices, six proper slices were selected.

Statistical analysis was performed using SPSS (Statistical Package for Social Sciences), version 20.0. The results were reported as frequency with corresponding percentage, mean and standard deviation (SD) from the mean. Chi-square $\left(\chi^{2}\right)$ Test was used to see the association between two categorical variables, while Unpaired t-Test and ANOVA statistics were used to compare any continuous variables between two groups and three groups/categories respectively. The level of significance was set at $5 \%$ and $p$-values $<0.05$ was considered statistically significant.

\section{RESULTS:}

Age distribution of the subjects with respect to sex shows that nearly two-thirds $(63.3 \%)$ of the female subjects were 30 or younger than 30 years old, whereas $50 \%$ of the male subjects were early middle-aged ( $p=0.110)$. The mean ages of the male and female subjects were 34.2 and 29.8 years respectively (Table $\mathrm{I}$ ).

The mean lengths of frontal horn of right and left lateral ventricles in male subjects were significantly greater than those in female subjects $(p=0.002$ and 
$p=0.001$ respectively). Likewise, the right and left ventricular bodies in male subjects were significantly longer than those of their female counterparts $(p=0.033$ and $p=0.012$ respectively (Table II). Table III shows that the length of frontal horn of the lateral ventricles increases with age up to 40 years in both right and left ventricles and then it begins to decrease. The mean lengths of frontal horn of right lateral ventricles at ages 30 or $<30,31-40$ and $>40$ years were $27.25,28.74$ and $26.0 \mathrm{~mm}$ respectively and were significantly heterogeneous $(p=0.049)$. The mean lengths of frontal horn of left lateral ventricles at the same age intervals were 27.57, 28.93 and $27.19 \mathrm{~mm}$ respectively, although they were not significantly different $(p=0.141)$.

Table IV shows that the mean lengths of body of right and left lateral ventricles at ages 30 or $<30$, $31-40$ and $>40$ years were $40.40,43.98,45.11 \mathrm{~mm}$ and $41.06,44.52$ and 45.21 respectively indicating that lengths increase linearly with the increase in age. The three measures of length of body of right and left lateral ventricles were significantly different $(p=0.001$ and $p=0.001$ respectively).

\begin{tabular}{lccc|} 
Table I. Age distribution between male and female sexes \\
\cline { 2 - 3 } Age (years)* & \multicolumn{2}{c}{ Sex } & p-value \\
\cline { 2 - 3 } & $\begin{array}{c}\text { Male } \\
(\mathrm{n}=30)\end{array}$ & $\begin{array}{c}\text { Female } \\
(\mathrm{n}=30)\end{array}$ & \\
$\leq 30$ & $11(36.7)$ & $19(63.3)$ & \\
$31-40$ & $15(50.0)$ & $8(26.7)$ & 0.110 \\
$>40$ & $4(13.3)$ & $3(10.0)$ & \\
Mean $\pm \mathrm{SD}^{\#}$ & $34.2 \pm 9.9$ & $29.8 \pm 8.7$ &
\end{tabular}

Figures in the parentheses indicate corresponding $\%{ }^{*} \chi^{2}$ was done to analyze the data.

\#Data were analyzed using Unpaired t-Test and were presented as mean \pm SD.

Table II. Findings of different parameters of lateral ventricles according to sex

\begin{tabular}{|c|c|c|c|}
\hline \multirow{2}{*}{$\begin{array}{l}\text { Parameters of } \\
\text { lateral ventricles" }\end{array}$} & \multicolumn{2}{|c|}{ Sex } & \multirow[b]{2}{*}{ p-value } \\
\hline & $\begin{array}{l}\text { Male } \\
(n=30)\end{array}$ & $\begin{array}{r}\text { Female } \\
(\mathrm{n}=30)\end{array}$ & \\
\hline $\begin{array}{l}\text { Length of frontal horn of right lateral } \\
\text { ventricle }(\mathrm{mm})\end{array}$ & $28.82 \pm 2.56$ & $26.54 \pm 2.9$ & 0.002 \\
\hline $\begin{array}{l}\text { Length of frontal horn of left lateral } \\
\text { ventricle }(\mathrm{mm})\end{array}$ & $29.31 \pm 2.53$ & $26.79 \pm 2.44$ & 0.001 \\
\hline Length of right ventricular body (mm) & $43.33 \pm 3.25$ & $41.52 \pm 3.13$ & 30.033 \\
\hline Lengthof left ventricular body (mm) & $44.43 \pm 3.46$ & $42.32 \pm 3.22$ & 0.012 \\
\hline
\end{tabular}

\#Data were analyzed using Unpaired t-Test and were presented as mean \pm SD.

\begin{tabular}{|c|c|c|}
\hline \multirow{2}{*}{$\begin{array}{l}\text { Age } \\
\text { (years) }\end{array}$} & \multicolumn{2}{|c|}{ Length of frontal horn of lateral ventricles $(\mathrm{mm})$} \\
\hline & Right & Left \\
\hline$\leq 30$ & $27.25 \pm 2.70$ & $27.57 \pm 2.48$ \\
\hline $31-40$ & $28.74 \pm 2.89$ & $28.93 \pm 2.89$ \\
\hline$>40$ & $26.00 \pm 3.32$ & $27.19 \pm 3.15$ \\
\hline$p$-value & 0.049 & 0.141 \\
\hline
\end{tabular}

\#Data were analyzed using ANOVA statistics and were presented as mean \pm SD.

Table IV. Association between age and length of body of lateral ventricles

\begin{tabular}{|c|c|c|}
\hline \multirow{2}{*}{$\begin{array}{l}\text { Age } \\
\text { (years) }\end{array}$} & \multicolumn{2}{|c|}{ Length of body of lateral ventricles $(\mathrm{mm})$} \\
\hline & Right & Left \\
\hline$\geq 30$ & $40.40 \pm 3.38$ & $41.06 \pm 3.64$ \\
\hline $31-40$ & $43.98 \pm 1.75$ & $44.52 \pm 1.83$ \\
\hline$>40$ & $45.11 \pm 0.69$ & $45.21 \pm 1.15$ \\
\hline$p$-value & 0.001 & 0.001 \\
\hline
\end{tabular}

\#Data were analyzed using ANOVA statistics and were presented as mean \pm SD.

\section{DISCUSSION:}

The human nervous system is the most complex, widely investigated \& less adequately understood physical system known to mankind. ${ }^{19}$ According to Taveras and Wood $^{22}$ the lateral ventricular contours are relatively constant except occipital horns. Alteration in the brain with ageing has been focused in many investigations. A degree of asymmetry in two lateral ventricular contours is common, partly because of anatomical difference and partly because of obliquity of the head. ${ }^{23}$ Considering the asymmetry of the two lateral ventricles, the amount of cerebrospinal fluid also alters because of the change in volumetric capacity. The volumetric changes in the lateral ventricles have been found in diseases like Schizophrenia. ${ }^{24}$ This morphometric study of lateral ventricles was conducted based on measurements of MRI of brain which were then correlated with different age and sex groups, with a view to obtain the parameters of normal healthy adults in our population.

In the present study, half $(50.0 \%)$ of the study cases was 18-30 years old with mean age of the patients being $31.5 \pm 9.6$ years (range: 18 to 50 years). Male subjects were a bit older than their female counterparts with mean ages of males and females 
were 34.2 and 29.8 years respectively. The frontal horns of right and left lateral ventricles in male subjects were significantly longer than those in female subjects $(p=0.002$ and $p=0.001$ respectively), which were on an average 1-1.5 mm less than those found in the study of Medora and Prashanth $^{19}$ (measured by CT scan) and on an average 1-2 $\mathrm{mm}$ less than those reported by Mallika ${ }^{25}$ by CT scan. Although, there is no clear-cut explanation of the difference between the two studies, except that the present study was done by MRI, where several slices were taken and the best section was selected. Moreover, the sample size of present study was only 60, whereas the sample size in the study of Mallika25 was 200 and that in the study of Medora and Prashanth ${ }^{19}$ was 1000 . It was also observed that the length of frontal horn of the right lateral ventricles increases with age up to 40 years and then it started decreasing and the changes in different age categories within group were significantly different $(p=0.049)$. The mean lengths of frontal horn of left lateral ventricles also assumed a similar pattern of change from $27.57 \mathrm{~mm}$ at age $\leq 30$ years, $28.93 \mathrm{~mm}$ between ages $31-40$ years and $27.19 \mathrm{~mm}$ after 40 years of age, although the difference was not statistically significantly $(p=0.141)$.

In our study, the ventricular bodies of both the lateral ventricles in male subjects were relatively long compared to those in females ( $p=0.033$ and $p=0.012$ respectively). This finding was in agreement with that of Mallika. ${ }^{25}$ Irrespective of sex, the mean length of right and left ventricular body was significantly different in different age groups $(p=0.001)$. In our study increase in the length of body of both lateral ventricles showed a linear trend with age, which fairly compares with study of Mallika. ${ }^{25}$

In the present study, the mean lengths of right and left ventricular body was about ${ }^{6} \mathrm{~mm}$ less than that found in the study of Mallika, because in present study, the measurement of ventricular body was taken by deducting the length of frontal horn from the length measured from the tip of the frontal horn to atrium. But in the study of Mallika, done by CT scan, the measurement was taken from interventricular foramen to atrium. In contrast, Medora and Prasanth ${ }^{19}$ showed that the lengths of right and left ventricular body to be 5-6 mm less than those found in the present study. This variation might be due to difference in sample sizes betweem the two studies, because their study was carried out on 1000 patients.

\section{CONCLUSION:}

The present study concluded that the lateral ventricles vary in size within certain limit according to age, sex and laterality. All the parameters of lateral ventricles (length of frontal horn, length of ventricular body) were significantly larger in males than those in their female counterparts. While, the length of frontal horn of the lateral ventricles increases in size up to the early middle-age and thereafter shrinks, the length of ventricular body bears a linear relationship with age. The present study serves as baseline parameter regarding the size of normal lateral ventricles of human brain which would help to detect its normal variation in different ethnic groups and abnormal variations in different pathological conditions.

\section{REFERENCES:}

1. Purves D, Augustine GJ, Fitzpatrick D, Hall WC, Lamantia AS, McNamara JO et al. Neuroscience (third edition), Sinauer Associates Inc, ISBN 0-87893-725-0, 2004.

2. Hill MA. Neural-Ventricular System Development. Retrieved October 21, 2013, http://php. med.unsw.edu. au/embryology/index. php?titleNeuralVentricularSyste mDevelopment.

3. Glydensted C. Measurement of normal ventricular system and hemispheeric sulci of 100 adults with Computerised tomography. Neuroradiology 1977;14: 183-92. 57.

4. Gawler J, Bull JWD, Du Boulay GH, Marshall J. Computerized axial tomography: the normal EMI scan. Jour of Neural, Neurosurgery and Psy 1975;38: 935-47.

5. Peper JS, Brouwer RM, Boomsma DI, Kahn RS, Hulshoff Pol, HE. Genetic influences on human brain structure: A review of brain imaging studies in twins. Human Brain Mapping 2007;28:464.

6. Allen JS, Damasio $\mathrm{H}$ and Grabowski TJ. Normal neuroanatomical variation in the human brain: an MRI-volumetric study. American journal of physical anthropology 2002;118(4):341-58. 
7. Andreasen NC, Smith MR, Jacoby CG, Dennert JW, Olsen SA. Ventricular enlargement in schizophrenia: Definition and prevalence. Am J of Psy 1982;139: 292-296.

8. Kido DK, Caire ED and Le May M. Temporal lobe atrophy in patients with Alzheimer's disease: ACT study. Am Jour of Neuroradiology 1989;10:551-555.

9. Huber SJ, Chakeres DW, Paulson GW. Magnetic resonance tmagmgm Parkinson's disease. Arch Neural 1990;47: 735-737.

10. Corsellis JAN. Greenfield's Neuropathology. In: Ageing and the dementias. Arnold London 1976:797-848.

11. Creasey $\mathrm{H}$ and Rapoport SI. The ageing human brain. Ann of Neur 1985;17:2-10.

12. Mc Rae DL, Vinken PJ, Brujn GW. Hand book of Clinical Neurology. In: Radiology in Epilepsy 1974;15:530-558.

13. Schochet SS. Neuropathology of ageing. Neur Clinof $N$ Am 1998;16(3):569- 580.

14. Scott ML, Golden CJ, Ruedrich SC and Bishop RJ. Ventricular enlargement in major depression. Psy Res 1983;8:91-93.

15. LeMay M. Radiological changes of the ageing brain and skull. Am Jour Of Roentgenology 1984;5:383-389.

16. Rohlfing T, Sullivan EV,Pfefferbaum A. Deformationbased brain morphometry to track the course of alcoholism: differences between intra-subject and inter-subject analysis. Psychiatry Res 2006;146(2): 157-70.
17. Monte SM. Disproportionate atrophy of cerebral matter in chronic alcoholics. Arch Neural 1988;45(9):990-2.

18. Losowska-Kaniewska D \& Oles A. Imaging examinations in children with hydrocephalus. Adv Med Science 2007;52(1):176-9.

19. Medora DC, Prashanth NE. Morphometric study of the ventricular system of brain by computerised tomography. Journal of Anatomical Society of India 2007;56(1):19-24.

20. Kulkarni NV. Clinical Anatomy for students problem solving Approach. $1^{\text {st }}$ ed. New Delhi, India: Jaypee Brothers Medical Publishers (p) Ltd; 2007:438-9.

21. Garret WJ, Kossoff $G$ and Warren PS. Cerebral ventricular size in children: a two dimensional ultra sonic study. Radiology 1980;136(3):711-5.

22. Traveras JM and Wood EH. Diagnostic neuropathology. $2^{\text {nd }}$ ed. In: Intracranialpneumography, 1976;1:290-400.

23. Gawler J, Bull JWD, Du Boulay GH and Marshall J. Computerized axial tomography: the normal EMI scan. Jour of Neural, Neurosurgery and Psy 1975;38:935-47.

24. Srijit D and Shipra P. Anatomical study of anomalous posterior horn of lateral ventricle ofbrain and its clinical significance. British LekListy 2007;108(9):422-4.

25. Mallika B. Morphometric study of lateral ventricles of the brain by computerized tomography and dissection method. Department of Anatomy, Mysore Medical College \& Research Institute. Myscore 2011;570:1-90. 